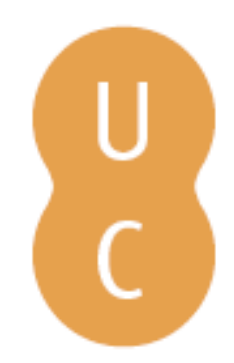

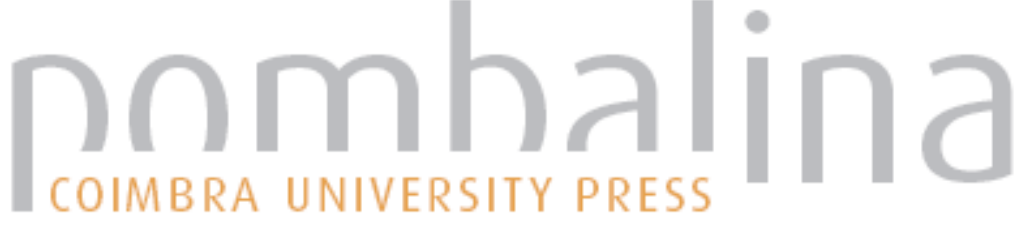

\section{Forest fire detection wireless sensor node}

Autor(es): $\quad$ Sakr, George E.; Ajour, Rafik; Khaddaj, Areej; Saab, Bahaa; Salman, Alaa; Helal, Ola; Elhajj, Imad H.; Mitri, George

Publicado por: Imprensa da Universidade de Coimbra

URL persistente:

URI:http://hdl.handle.net/10316.2/34290

DOI:

DOI:http://dx.doi.org/10.14195/978-989-26-0884-6_153

Accessed : $\quad$ 26-Apr-2023 11:28:32

A navegação consulta e descarregamento dos títulos inseridos nas Bibliotecas Digitais UC Digitalis, UC Pombalina e UC Impactum, pressupõem a aceitação plena e sem reservas dos Termos e Condições de Uso destas Bibliotecas Digitais, disponíveis em https://digitalis.uc.pt/pt-pt/termos.

Conforme exposto nos referidos Termos e Condições de Uso, o descarregamento de títulos de acesso restrito requer uma licença válida de autorização devendo o utilizador aceder ao(s) documento(s) a partir de um endereço de IP da instituição detentora da supramencionada licença.

Ao utilizador é apenas permitido o descarregamento para uso pessoal, pelo que o emprego do(s) título(s) descarregado(s) para outro fim, designadamente comercial, carece de autorização do respetivo autor ou editor da obra.

Na medida em que todas as obras da UC Digitalis se encontram protegidas pelo Código do Direito de Autor e Direitos Conexos e demais legislação aplicável, toda a cópia, parcial ou total, deste documento, nos casos em que é legalmente admitida, deverá conter ou fazer-se acompanhar por este aviso.

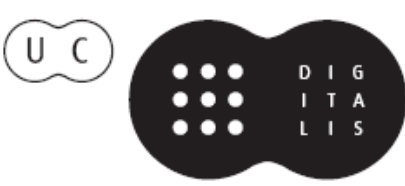




\section{ADVANCES IN}

Forest Fire

\section{RESEARCH}

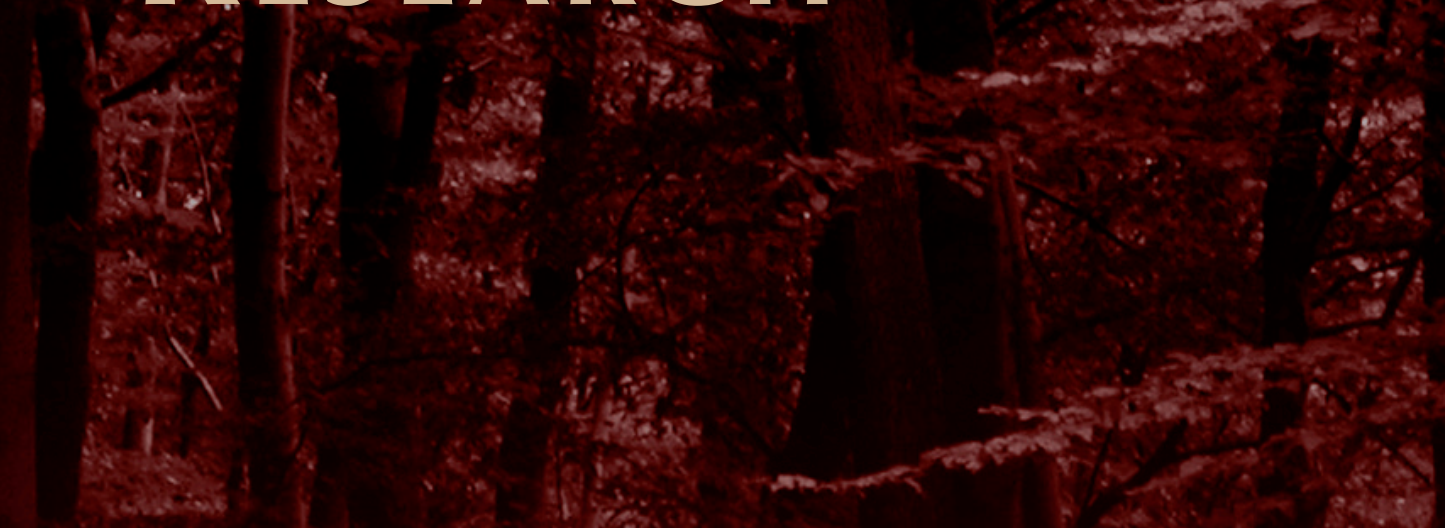

\section{DOMINGOS XAVIER VIEGAS}

\section{EDITOR}




\title{
Forest fire detection wireless sensor node
}

\author{
George E. Sakr ${ }^{\mathrm{a}}$, Rafik Ajour ${ }^{\mathrm{a}}$, Areej Khaddaj ${ }^{\mathrm{a}}$, Bahaa Saab ${ }^{\mathrm{a}}$, Alaa Salmana, Ola Helala ${ }^{\mathrm{a}}$, Imad H. \\ Elhajj ${ }^{\mathrm{a}}$, George Mitri ${ }^{\mathrm{b}}$
}

${ }^{a}$ Electrical and Computer Engineering Department, American University of Beirut, Beirut, Lebanon, ges07@aub.edu.lb, rafikajour@gmail.com, areej.khaddaj@gmail.com, bahaa.saab@gmail.com, alaasalman@gmail.com, olahelal@hotmail.com, ie05@aub.edu.lb

${ }^{b}$ Institute of Environment, University of Balamand, Tripoli, Lebanon, george.mitri@balamand.edu.lb

\begin{abstract}
Wireless sensor networks have attracted a great deal of research due to the wide range of applications that are enabled by such networks. Sensor networks are used for ecological monitoring, military surveillance and biomedical detection. This paper describes a design of a wireless sensor node to be used for early forest fire detection; it utilizes the WSN principle where each node is a sensing device with various sensors attached, powered by solar recharging and supports wireless data transmission. Each one of these nodes sends its collected data through the network to reach a sink node. The latter has a direct link with a base station (weather station, civil defence operation room, or scientific research center). The base station analyses the received data and takes the decision accordingly to raise a fire alarm or not. The main parameters involved in the decision making are smoke, CO, temperature, humidity and methane gas. This paper details the design as well as the experimental activities which demonstrated that this device is capable of early forest fire detection.
\end{abstract}

Keywords: Forest Fire, Detection, Wireless Sensor Network, Energy Efficient.

\section{Introduction}

Forest fires pose a menacing danger to the socio-economical, ecological, and environmental aspects of a community. Moreover, forest fires cause severe "ecological imbalances" through endangering the natural habitats of animals, disrupting the food chain in a vast area that exceeds the burned zone, reducing ground water levels, polluting rivers, and preventing vegetation from growing in burned zone. More specifically increasing fire frequency and severity, threatening forest ecosystems and economic development [Mitri, 2009]. All this gives rise to the urgent need to detect forest fires as fast as possible, so as to limit these effects.

Systems used for forest fire detection can be divided into three groups based on where the sensors are deployed: aerial, terrestrial, or combination. It is worth noting that in many cases similar sensors are used in aerial and terrestrial systems. However, depending on the location of deployment there might be different advantages and disadvantages.

\subsection{Aerial Forest Fire Detection}

The areal detection is subdivided into two main categories: Satellite Systems and Autonomous Aerial Vehicles. There are two types of satellites that appear in the context of forest fire detection. These are the geostationary satellites and the polar orbiting satellites. The geostationary satellites maintain a higher temporal resolution compared to the orbiting ones. This is the reason why geostationary satellites have an advantage over the polar orbiting satellites in near-real time active forest fire detection. In most cases the satellites are used with a base station that collects the data sent by the satellite(s) and runs the analysis [Manyangadze, 2009, Zhou, 2004, Kelh, 2000, Abuelgasim, 2002]. Satellite imaging is used by several agencies for detecting and tracking fires; such as the Canadian Wildland Fire Information System of the Canadian Fire Service. Three well known satellite systems used for fire detection are the (AVHRR) launched by the National Oceanic and Atmospheric 
Administration (NOAA) in 1998, the Moderate Resolution Imaging Spectroradiometer (MODIS) launched by NASA in 1999 on board of the Aqua satellite and the National Aeronautics and the Space Administration's Moderate Resolution Imaging Spectroradiometer (MODIS). The use of satellites for forest fire detection and monitoring remains a dominant option. Yet, this system suffers from a set of disadvantages:

- There is a minimum detectable fire size, usually $0.1 \mathrm{ha}$. This means that there is some delay to detect the fire, which is at least equal to the time it takes for the fire to go beyond 0.1 ha.

- The accuracy of the system is within $1 \mathrm{~km}$ of the actual location of the fire.

- Satellites typically provide images of the monitored area every 1 to 2 days, which is a limitation as fires could go undetected for a long time.

- Clouds greatly affect the Top of Atmosphere temperature as they may lower the temperature measured by the satellite. The interpretation being that clouds usually have cold tops and hence low brightness temperature; thus, fires under these clouds are missed.

- Selection of the processing algorithm varies for different sensors with each having its specific limitations.

Autonomous Aerial Vehicles use a helicopter with infrared and visual cameras [Dios, 2005, Casbeer, 2005]. These helicopters are called "Autonomous Aerial Vehicles" or "Unmanned Aerial Vehicles" (UAVs). A base station is needed as well where the collected data is analyzed. Fire detection is initiated in missions where a UAV fleet embarks on patrolling the forest in question. In order to decrease the probability of false alarms, this system relies on the combined results obtained from the analysis of infrared and visual images. Navigation sensors are installed on the UAV to compute the position and the orientation of the cameras. These calculated positions are then collected in order to locate the actual fire. This system suffers from some disadvantages such as:

- Covering large forests requires the use of a larger number of UAVs or a longer flight time per vehicle, which means more consumption of fuel yielding a higher overall operational cost.

- Monitoring a forest is very difficult when unfavourable or extreme weather conditions are present. In addition, limited visibility when smoke is present.

- Assessing fires will vary significantly depending on the topology of the forest in question.

- Scheduling of the flights poses another concern in this mechanism since issuing UAV flights throughout the day will result in a waste of resources and in an increase in cost.

- Radio communication can be hindered in mountainous areas

- Cost of UAV's starts at around 7000\$ and they require specialized personnel to operate and maintain them.

\subsection{Terrestrial Forest Fire Detection}

Several terrestrial systems have been investigated which include: video surveillance, radio acoustic sounding, fiber optic sensor network, wireless sensor network and a combination of the above.

Video surveillance systems are the most widely used for forest fire detection [Kovcs, 2004, Losso, 2006, Stipanicev, 2006, Bodrozic, 2006, Dios, 1999, Arrue, 2000, Bosch, 2007]. In this system, camera sensors are mounted on communication towers that are placed on a location overlooking a large part of the forest. It is not uncommon for cameras to be mounted on towers of elevation often surpassing $30 \mathrm{~m}$, making maintenance and even initial deployment a non-trivial affair. In order to provide a full view of the forest, or a specific portion of it, a rotational mechanism is installed to enable the camera 
to rotate. The images obtained by the sensors are processed to detect smoke. This is made possible by the use of algorithms that takes into consideration atmospheric conditions.

Radio Acoustic Sounding System (RASS) refers to the use of wave radiation in order to obtain the atmospheric structure. This system utilizes two main devices which are the radio with fire watch towers and the acoustic source [Sahin, 2009]. The approach is to form thermal maps of forest areas for the detection of potential fires. This relies on the fact that radio acoustic sounding techniques have much higher sensitivity to temperature changes and can remotely provide more accurate air temperature measurements. The process of temperature measurement using acoustic sound waves is made available by a Sonar, or acoustic radar, that operates by transmitting acoustic pulses into the atmosphere and detecting echoes backscattered from atmospheric thermal inhomogeneites. This technique is very effective and reliable and it is believed that, in terms of accuracy, it surpasses any other fire detection technique. Yet, it still has several disadvantages and technical difficulties that are:

- The deployment strategy of this system is critical to the performance. This is due to the fact that echoes in collected data are caused by ground clutter.

- It is reported that the scanning area is to be limited to a certain height that is just above the trees.

- The performance is sensitive to the frequency matching and the power of the signal. The optimal results are only obtained once the frequency and the power of the acoustic signals are determined, taking into consideration several issues such as the forest surface density and the distance between the radar and acoustic sources.

Fiber Optic Sensor Network uses a network of fiber optic sensors based on "Fiber Bragg Grating" (FBG) devices, distributed sensors and gas analyzers, and optoelectronic piloting unit for the grid of fiber optic sensors [Corsi, 2006]. This system is composed of FGB temperature sensors, an FBG acquisition assembly to collect data from FBG sensors, distributed fiber optical sensors to collect distributed temperature variation over the fiber, roads upon which to lay the cable through the forest, and gas sensors and their acquisition unit. The number of sensors and the length of the fiber optic cable depend on the nature of the forest. The FBG temperature sensors measure the temperature values in the presence of fire. The gas sensors collect samples of air, measure the content for $\mathrm{CH} 4$, and report the results to their respective acquisition unit. The advantage of this system is that the effect of temperature variation on the wavelength of fiber optics can be exploited to generate ultra-stable temperature sensors. This system has two main drawbacks:

- The fiber optic cables need to be installed throughout the forest on a special type of road or path.

- Crown fires take longer time to be detected, if ever, depending on the height of the trees. This is the case since the cables are laid on ground level.

Recently, a promising technology has emerged based on Wireless Sensor Networks [Hefeeda, 2007]. Sensible Solutions Sweden AB developed robust and environmentally friendly sensors, which can be placed in trees. When high temperatures are detected for a few seconds these sensors transmit a radio signal alerting of the possibility of a fire. The disadvantage of such a system is that it does not provide any environmental measurements which can be used to assess the risk of a fire starting. In addition, they are based on detecting high temperatures, which might take a long time to reach a sensor and which implies sensors only detect fires that do reach them. Temperature, relative humidity and barometric pressure where used in a wireless sensor network to demonstrated experimentally that variations in these parameters could be used to detect fires [Doolin, 2005]. The Forest Fire Surveillance System was designed and deployed in South Korea [Son, 2006]. The nodes used measure temperature, humidity and light. Neither of these approaches used smoke detection to improve the performance of the network. In addition, neither of the references discussed the practical requirements of packaging needed to deploy the sensor network. Several papers had mentioned wireless sensor networks as a tool 
for forest fire detection [Yu, 2005, Chaczko, 2005]. However, these papers focused on theoretical issues related to sensor networks in general such as in-network processing and data collection. The work in both papers was theoretical with no actual nodes or network being designed and deployed. Also, they had minimal contribution to the task of early forest fire detection. Combination Forest Fire Detection systems integrate the use of a network of optical cameras linking to a multi-layer GIS database operated by Control Operating Center [Tsiourlis, 2009]. This is referred to as the "SITHON" system. The SITHON system consists of a wireless network of optical cameras and an airborne fire detection system based on a fully digital thermal imaging sensor. In turn, the network of optical sensors consists of monitoring towers, transmitters, and wireless transmission links up to an integrated GIS environment. This system shares the drawbacks of all of its components.

In addition to the above mentioned systems, is the none traditional Mobile Biological Sensors [Sahin, 2007]. Animals living in a forest are used to assist in the early detection of the fire. These animals are technically referred to as "Mobile Biological Sensors" (MBSs). This system is composed of the MBSs, thermal and radiation GPS equipped sensors, access points for wireless communication, and a central computer system. Data is checked for sudden movement of group of animals, which is believed to be a result of panic among those animals. There are some technical limitations involved in this method:

- Animals and sensors should be chosen in accordance with the characteristic of the forest in question and the forest fire type to be detected. For example, crown fires, surface fires, and ground fires cannot all be detected by installing sensors on reptiles.

- Sensor selection depends on the animal species that is chosen.

- Powering these sensors is another concern as they are expected to operate for a long time.

In this paper we present the design and evaluation of a wireless sensor node for the early detection of forest fires. The rest of the paper is organized as follows. Section 2, describes the proposed design, the operation and the packaging of the device. Section 3 reports the experimental results.

\section{Methods}

In order to achieve fire detection within a reasonable time, a number of detection devices (including all its subcomponents) should be deployed in different strategic spots in the forest. This implies that there should be a wireless network linking all these devices together. All the data and signals collected, shared, and transmitted between these devices ought to be sent to a remote base station, located somewhere inside or even outside the forest itself. This base station may be a civil defense office, weather station, office for statistics and analyses, or any concerned authority. Therefore, in order to link this sub-network in the forest to that base station, at least one of the devices in the forest has to serve as a gateway or a "sink" of all the signals and data emanating from the forest devices (sources) to their final destination. Note that these sinks are detection devices as well. The only two differences are that they can communicate with the base station and they have their own schedule of operation. The number of these gateways depends on the topography of the terrain, area of the forest, number of regular devices inside it, and the amount and frequency of data to be sent. The general structure of the network is shown in Figure 1. The figure shows a typical architecture of a deployed network where a number of nodes are mounted on trees or poles. These nodes report to a base station with Internet access to send remote alerts of the occurrence of a forest fire. 


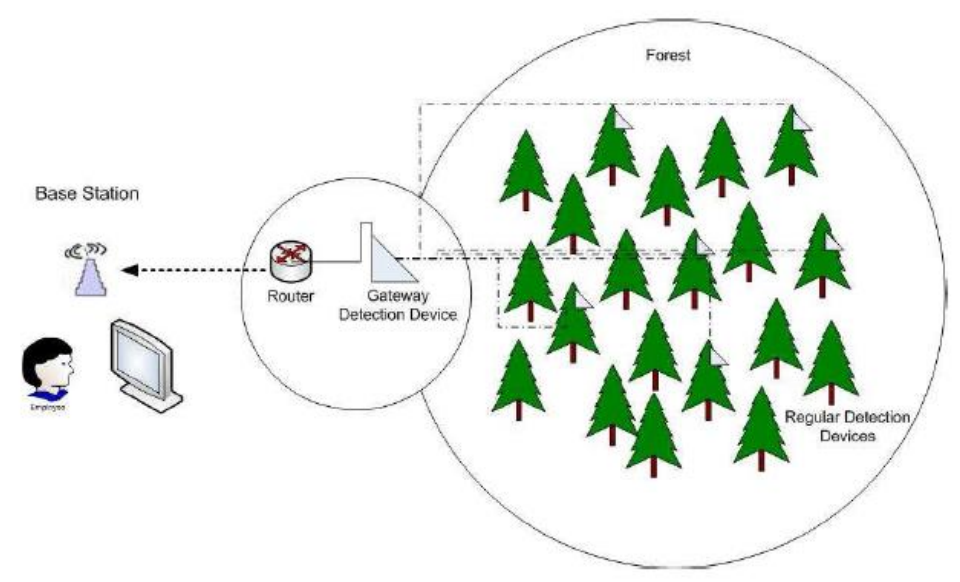

Figure 1. Network Structure

This paper discusses the design and implementation of the nodes used for fire detection. The deployment strategy is beyond the scope of this paper. The device makes use of the components shown in Figure 2.

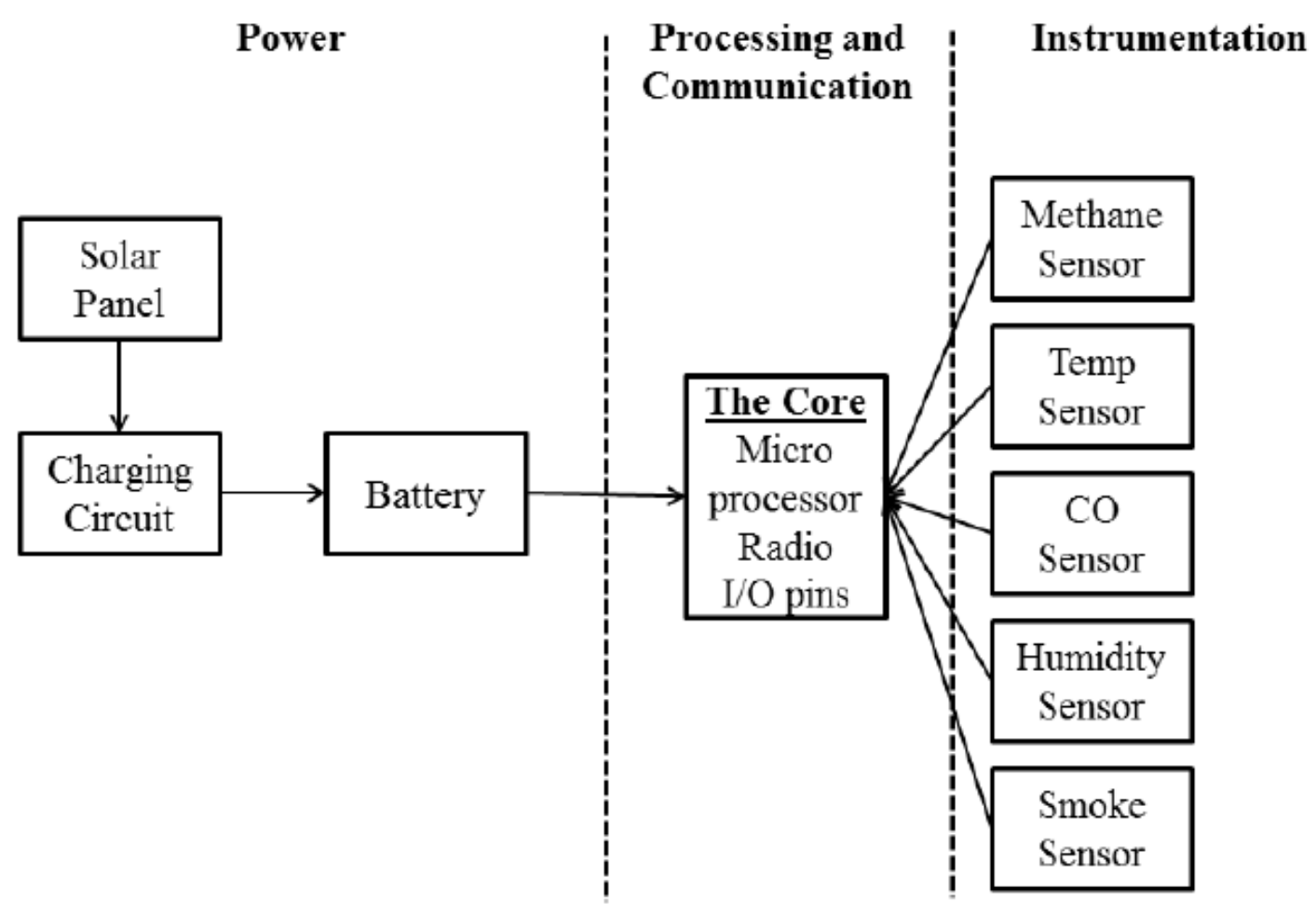

Figure 2. Device's Components

Smoke sensor can provide great help when detecting fires since smoke is the most common and spontaneous product of fire. The smoke sensor chosen is a light Scattering Photoelectric Detector. This smoke sensor produces an output of $1.5 \mathrm{~V}$ with a response time which varies between 10 and 20 seconds depending on the concentration of smoke. 
Temperature sensor: When a forest fire occurs, huge masses of timber, shrubs, and various plants are burnt, releasing vast amounts of energy in the form of heat. This heat is dissipated in the surrounding atmosphere, causing an increase in temperature. Although this increase in temperature might be a couple of degrees, this can still be a valid indicator especially when combined with other factors. The temperature sensor used is the one built-in the Berkeley Mote (Tmote)

Humidity Sensor: Built-in the Tmote, the humidity has a significant impact on the reliability of the system design since high levels of relative humidity may deceive the smoke sensor, resulting in false alarms. So this sensor can be used to reduce false alarms.

CO Sensor: Carbon Monoxide (CO) is an evident gas released from a forest fire. The S+4CO by Sensor Direct has been used, this sensor is linear, it has a response less than $30 \mathrm{sec}$, with a resolution of 1 $\mathrm{ppm}$, and a range of 0-500 ppm. However, its sensitivity is considerably low ( $70 \mathrm{nA} / \mathrm{ppm})$. This implies that a very low output voltage is produced, even for the maximum input value. For instance, if the $\mathrm{CO}$ concentration was $500 \mathrm{ppm}$, then the output of the sensor would be $35 \mu \mathrm{A}$, which is an undetectable value by the Mote. To solve this issue, a special Potentiostatic circuit, recommended by National Semiconductor has been used. This circuit is shown in Figure \ref\{circuit\} and includes the LMP7721 amplifier which input bias current is only 3fA. The final output voltage of the circuit is the current value multiplied by 10000 , which end up being $350 \mathrm{mV}$, an easily detected value by the Mote.

Methane Sensor: Forest fires release huge quantities of combustible gases such as, Methane with average emission rate of $4.96 \mathrm{~g} / \mathrm{kg}$ of dry weight of trees burned. Other combustible gases have lower rates: $\mathrm{CH} 3 \mathrm{COOH}$ (3.96), $\mathrm{HCOOH}(2.61), \mathrm{CH} 3 \mathrm{OH}$ (2.06), $\mathrm{C} 2 \mathrm{H} 4$ (0.94), and $\mathrm{C} 2 \mathrm{H} 6$ (0.58). Therefore, among the combustible gases, it is most valuable to measure methane levels, in order to help in detecting forest fires. The Methane sensor chosen is the KGS 701 by Korea New Ceramics Co., Ltd. which has an input range of $(0-1001 \%$ LEL), with a sensitivity $27 \pm 5 \mathrm{mV} / \%$ methane and with a response rate less than $10 \mathrm{sec}$. This sensor also can detect a wide range of combustible gases, mainly propane, iso-butane and pentane.

Battery: a rechargeable Li-ion battery has been chosen. This battery is characterized by a high energy density, a long life cycle (around 300 to 500 cycles), a high drain capability and a fast charge capability. We have chosen a battery with an energy capacity close to $1800 \mathrm{mAh}$ and a voltage of $3.7 \mathrm{~V}$, since the mote operates on a voltage range of $2.1 \mathrm{~V}$ to $3.6 \mathrm{~V}$.

The Li-ion battery needs a special recharging circuit that guarantees its power functioning and protects it from being damaged. Several requirements are to be considered:

- Set a minimum threshold of input charging voltage.

- Maintain a constant charging voltage independent from the variation of the solar panel's output voltage.

- Stop charging when the battery if full

- Prevent the battery from discharging into the panels when the voltage is low

- Prevent an over-current to enter into the battery, which may damage it.

- To achieve the special charging, the most appropriate IC found was the LTC 1734 by LTC 1734 by Linear Technology, described as "A Lithium-ion Linear Battery Charger". Some of the characteristics of the LTC 1734 are:

- Programmable charge current: $50 \mathrm{~mA}$ to $180 \mathrm{~mA}$

- $1 \%$ accurate pre-set voltage: $4.2 \mathrm{~V}$

- Charge current monitor output for charge termination

- Automatic sleep mode with input supply removal

- Negligible battery drain current in shutdown

- Under-voltage lockout

- Self protection for over-current/over-temperature 
Linear Technology recommends a special circuit to include the LTC 1734 within. Figure 4 shows the LTC 1734 designed to deliver a current of $80 \mathrm{~mA}$.

The resistor connecting pin 4 to ground is the control element, which determines the delivered current, based on the following equation:

$$
I_{\text {Bat }}=\frac{375}{R_{\operatorname{Pr} o g}}
$$

Solar Panel: Solar energy is selected due to its higher energy density, simple implementation, reliability, and cost effectiveness. Six solar panels are used to deliver the appropriate energy needed; each rated at $3.7 \mathrm{~V}$ and $85 \mathrm{mAh}$. This bank of panels is connected as shown in figure 3.

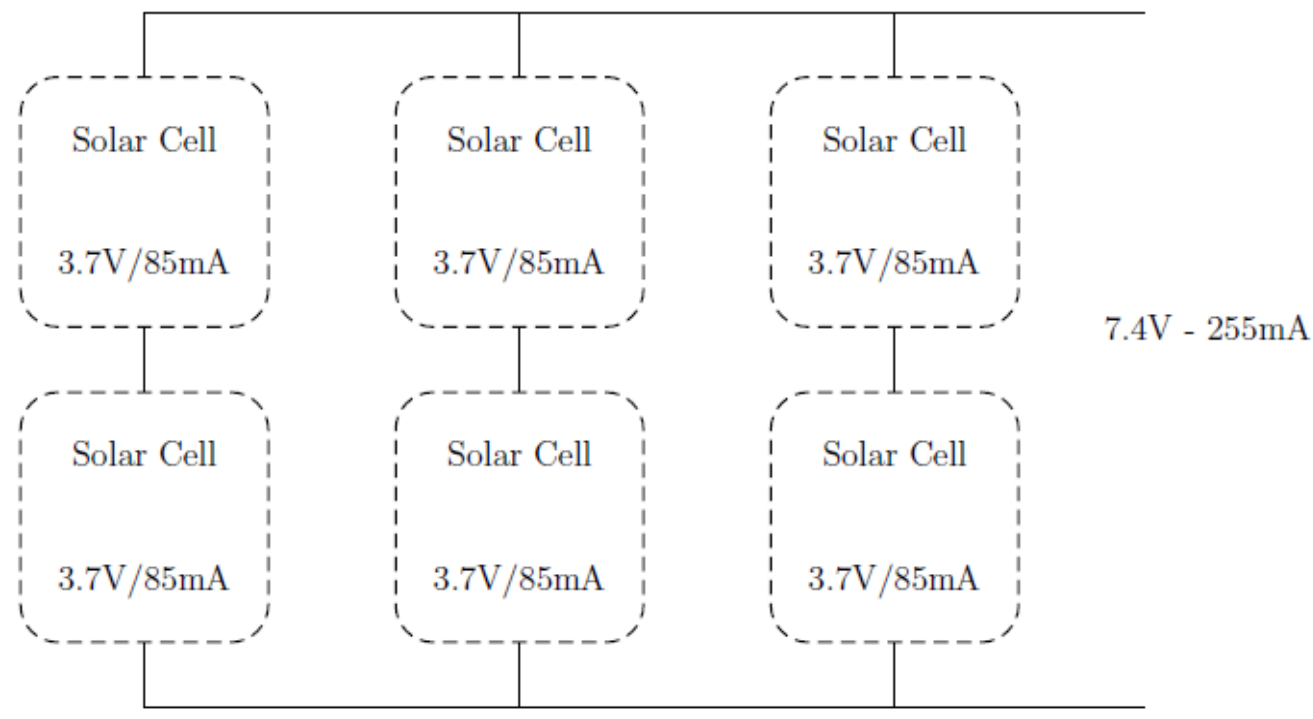

Figure 3. Solar Panel Connections

This configuration produces a nominal rated voltage of $7.4 \mathrm{~V}$ that is sufficiently higher than the required charging voltage of the battery.

Tmote Sky (Mote-developed by Berkeley University): The core of the node is the processing needed for the sensor outputs, communicating the data to the sink, and checking if there is a fire. The core includes a microcontroller to collect the data coming from the sensors and communicate them. This core is the mote named Tmote Sky that is ultra-low power device and was intended to be used in wireless sensor networks. The mote can be connected to the USB ports of the computer where it can be programmed. Besides, it includes Chipcon CC2420 radio for wireless communication that supports IEEE 802.15 .4 . It operates at $2.4 \mathrm{GHz}$ frequency, and it may communicate with other motes that use the same standard. Hence, the different motes can establish a network automatically upon booting up within their communication vicinity.

The Mote uses MSP430F1611 microcontroller that includes the MSP430 microprocessor produced by Texas Instruments. The 16-bit RISC processor features extremely low active and sleep current which reduces its power consumption. This permits the mote to run for years on a pair of AA batteries. Moreover, it can function on high level operating systems like the TinyOs. This eases the programming of the mote using the NesC language supported by TinyOs.

The module of the mote was designed to fit two AA batteries; however its operating voltage ranges between $2.1 \mathrm{~V}$ to $3.6 \mathrm{~V} \mathrm{DC}$. Whenever attached through the USB port, the mote takes its power from the computer. Its power consumption depends on its operation. Consequently, different types of sleep modes can be applied by stopping the components that consume power. 


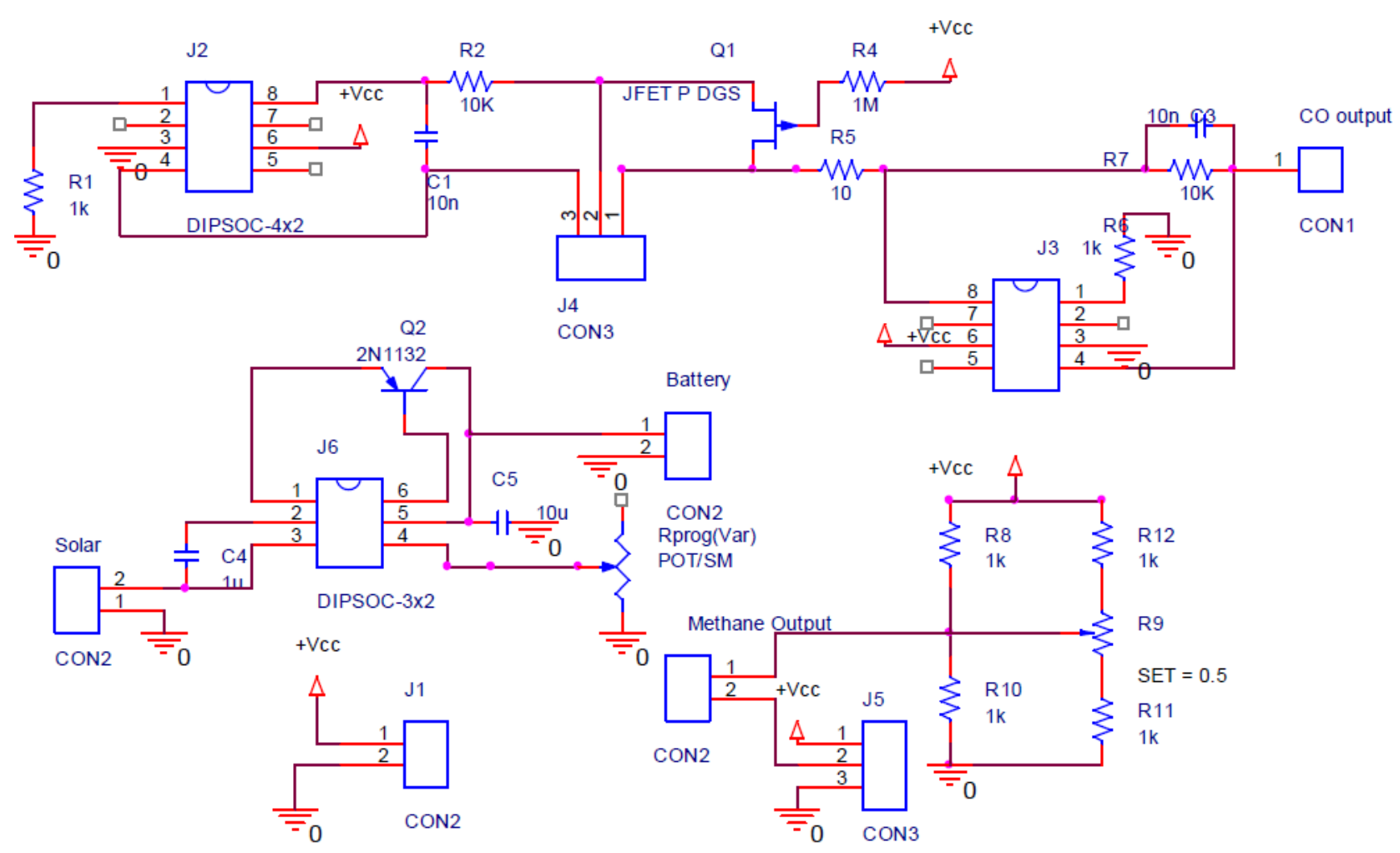

Figure 4. Circuit Design

\subsection{Design Operation}

The main implementation aspect of the mote is its software. The software consists of two main parts: the program on the nodes in the forest and the program on the sink (base station node). Each node shall sense the different parameters (methane, smoke, $\mathrm{CO}$, humidity and temperature) and send them in a single packet to the base station that reads and processes them. The IEEE802.15.4 wireless communication protocol permits automatic setup of the network between the motes that are within communication range. Thus any packet will be routed to its destination by the network itself. The routing supported by the motes was used without modification.

The program proceeds as follows: the sampling timer is initialized by the value set by the base station, whenever it is fired; it turns the output voltage on; this will power the $\mathrm{CO}$ and the methane sensor circuits. Then it will initialize a $1 \mathrm{~min}$ stabilizing timer that will wait for the sensors outputs to stabilize. After the stabilizing timer is fired the program acquires the output of the built-in sensors on the mote, the value of the operating voltage on the mote, and the output voltage of the methane, smoke and $\mathrm{CO}$ sensors. Finally all the read values are added to the packet and sent to the base station. The sampling timer can be configured by the base station. The inputs and outputs of the sensor are connected to the expansion pins of the mote where they can take power and send their outputs. The Mote will be in sleep mode when the sampling timer is running. See Figure 5 for the flowchart of the code.

For design reliability, the smoke sensor will remain always on as an existence of smoke will surely mean that there is fire and its output will be used as an interrupt that will awake the mote and send the alarm packets whenever there is smoke. For the methane, its output is the difference between high and low outputs. The two outputs are connected to the mote and their values are subtracted through the software. Both the Smoke and the CO sensors outputs are acquired directly. 


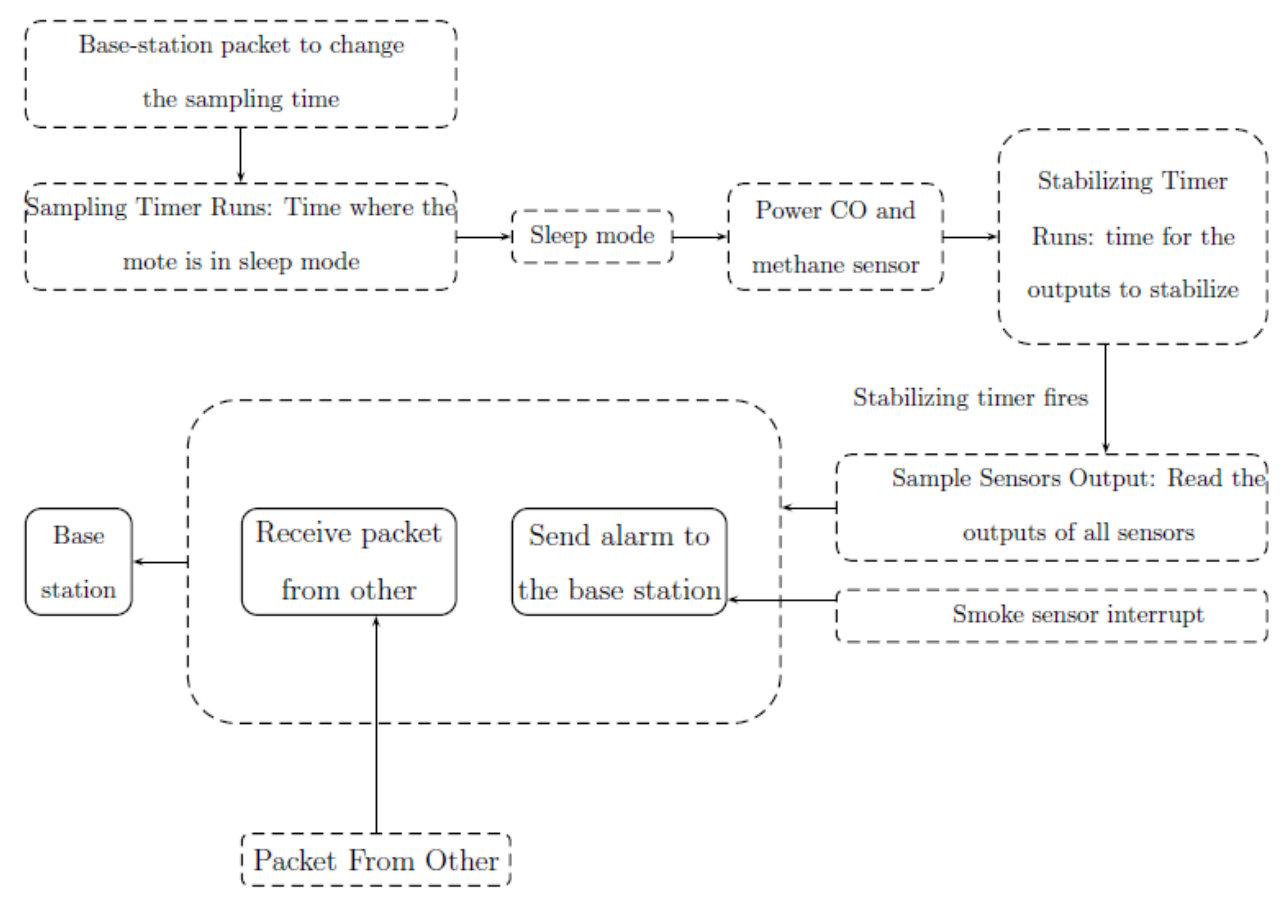

Figure 5. Script Flowchart

\subsection{Device Packaging}

The general shape of the package is right triangular prism where the sensors emerge from the bottom facing downwards. The top cover holds the solar panels and makes an angle of $34 \$^{\wedge} \mathrm{o} \$$ with the base of the package to increase the solar radiation. The device can be mounted on a pole or tree form the vertical side and its base will be parallel to the horizontal plane. One of the sides can be easily removed in case any component needs to be replaced, modified, or introduced. Figure 6 shows the finalized package.
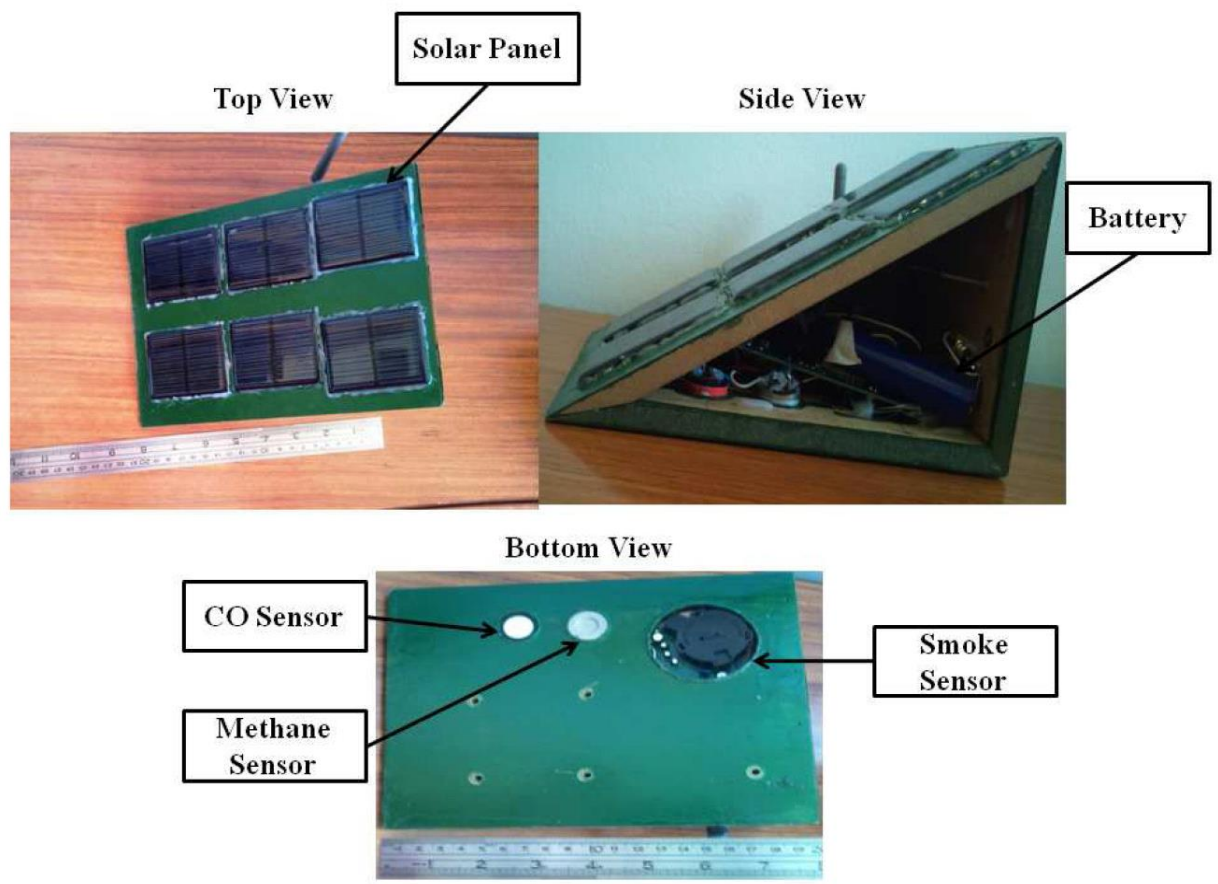

Figure 6. Fire Sensor Module Different Views 


\section{Results}

Tests were conducted for each sensor and fires were burnt in controlled conditions at different heights. Ash and paper were burnt at the vicinity of the smoke sensor to test its performance. Ten experiments were conducted and the resulting outputs are shown in Table 1.

Table 1. Smoke Sensor Performance T: time, $H$ : height, 1: fire detected, 0: fire missed

\begin{tabular}{|lc|c|c|c|c|c|c|c|c|c|c|c|}
\hline & $\mathrm{T}$ & $\mathrm{t}$ & $\mathrm{t}+1$ & $\mathrm{t}+2$ & $\mathrm{t}+3$ & $\mathrm{t}+4$ & $\mathrm{t}+5$ & $\mathrm{t}+6$ & $\mathrm{t}+7$ & $\mathrm{t}+8$ & $\mathrm{t}+9$ & Average \\
\hline $0.5 \mathrm{~m}$ & 0 & 1 & 1 & 1 & 0 & 1 & 1 & 1 & 1 & 1 & $80 \%$ \\
\hline $1 \mathrm{~m}$ & 1 & 0 & 1 & 1 & 1 & 0 & 0 & 1 & 1 & 1 & $70 \%$ \\
\hline $1.5 \mathrm{~m}$ & 0 & 1 & 0 & 0 & 1 & 1 & 1 & 0 & 1 & 0 & $50 \%$ \\
\hline
\end{tabular}

Table2 - CO Sensor Concentration in ppm T: time, H: height

\begin{tabular}{|c|c|c|c|c|c|c|c|c|c|c|c|}
\hline $\mathrm{H}$ & $\mathrm{t}$ & $\mathrm{t}+1$ & $\mathrm{t}+2$ & $\mathrm{t}+3$ & $\mathrm{t}+4$ & $\mathrm{t}+5$ & $\mathrm{t}+6$ & $\mathrm{t}+7$ & $\mathrm{t}+8$ & $\mathrm{t}+9$ & Average \\
\hline $0.5 \mathrm{~m}$ & 129.2 & 141.2 & 114.5 & 149.5 & 156.4 & 147.4 & 150.4 & 153.1 & 145.4 & 142.1 & 142.9 \\
\hline $1 \mathrm{~m}$ & 111.7 & 86.8 & 115.2 & 121.4 & 130.4 & 117.7 & 103.0 & 98.0 & 105.7 & 100.5 & 109.0 \\
\hline $1.5 \mathrm{~m}$ & 84.2 & 50.8 & 46.0 & 86.4 & 63.4 & 43.71 & 74.8 & 56.8 & 47.1 & 49.8 & 60.3 \\
\hline
\end{tabular}

Table 3- Methane Sensor - \% of air composition by volume T: time, H: height

\begin{tabular}{|c|c|c|c|c|c|c|c|c|c|c|c|}
\hline $\mathrm{H}$ & $\mathrm{t}$ & $\mathrm{t}+1$ & $\mathrm{t}+2$ & $\mathrm{t}+3$ & $\mathrm{t}+4$ & $\mathrm{t}+5$ & $\mathrm{t}+6$ & $\mathrm{t}+7$ & $\mathrm{t}+8$ & $\mathrm{t}+9$ & Average \\
\hline $0.5 \mathrm{~m}$ & 3.463 & 5.130 & 5.104 & 4.230 & 4.815 & 3.593 & 4.111 & 5.026 & 4.800 & 5.107 & 4.538 \\
\hline $1 \mathrm{~m}$ & 4.085 & 2.833 & 3.289 & 2.863 & 2.956 & 3.900 & 4.063 & 3.363 & 4.537 & 2.841 & 3.473 \\
\hline $1.5 \mathrm{~m}$ & 2.293 & 2.185 & 2.896 & 2.952 & 1.826 & 2.385 & 2.304 & 2.678 & 2.793 & 2.878 & 2.519 \\
\hline
\end{tabular}

The results recorded in Table 1 show that the smoke sensor succeeded in detection $80 \%, 70 \%$ and $50 \%$ of the time at $0.5 \mathrm{~m}, 1 \mathrm{~m}$ and $1.5 \mathrm{~m}$ respectively. The average amplitude of the output voltage generated by the smoke sensor varied from one experiment to another with an average value of $1.5 \mathrm{~V}$, which is easily digitized by the mote. It is also important to note that the detection is performed quickly and in close range which is necessary to detect small fires that satellites cannot detect.

Ten experiments of incomplete combustion were done to test the $\mathrm{CO}$ sensor with its circuit. A big piece of paper was slightly burnt and then inserted in a bottle. The bottle was closed and got filled with $\mathrm{CO}$. The bottle is then opened and exposed to the sensor. The output $\mathrm{CO}$ concentration is shown in Table 2.

The values obtained in Table 2 vary between 46ppm and 156ppm, with an average of 120ppm, which is the typical concentration of $\mathrm{CO}$ in such a fire. Moreover the concentration decreases as the distance between the sensor and complete combustion increases. The output voltage ranged between 100 and 
$130 \mathrm{mV}$, with an average value of $120 \mathrm{mV}$. Taking into consideration the $20 \mathrm{mV}$ offset, the output increase is $100 \mathrm{mV}$, which is a significant value, compared to the amount of released CO.

The methane sensor was tested using an unregulated methane source in 10 experiments. We exposed the output of the source to the membrane of the sensor with separation of about $10 \mathrm{~cm}$, and released the gas. The average response time was two seconds. The output voltage ranged between $80 \mathrm{mV}$ and $160 \mathrm{mV}$, with an average of $110 \mathrm{mV}$. These values signified that the sensor and circuit were working correctly. The percentage decreases as the distance between the sensor and the source increases.

It is worth noting that for all sensors the accuracy of measurement is not critical as the sensitivity. The detection works on processing change in normal operation to detect an increase of a gas. So the absolute value is not as important as the change in the sensor output.

\section{Conclusion}

This paper described a sensor node to be used for forest fire detection. The sensing device is characterized by various sensors attached to a mote, solar recharging mechanism, and wireless data transmission capability. The main parameters involved in the decision making are smoke, CO, temperature, humidity and methane gas. The results show high accuracy $(80 \%)$ of fire detection for close range and slightly lower but acceptable accuracy for higher ranges (60\%). As for future work, this device can be used for forest fire prediction in addition to detection. Moreover, the deployment plan and strategy has to be developed to optimize the operation of the overall network.

\section{Acknowledgment}

This research was funded by the Association for Forests, Development and Conservation (AFDC), American University of Beirut University Research Board, Dar Al-Handassah (Shair I\& Partners) Research Fund and the Rathman (Kadifa) Fund.

\section{References}

Abuelgasim, 2002 Abuelgasim, A., Fraser, R., 2002. Day and night-time active fire detection over north america using noaa-16 avhrr data, in: Geoscience and Remote Sensing Symposium, 2002. IGARSS'02. 2002 IEEE International, IEEE. pp. 1489-1491.

Losso, 2006 Andrea Losso, Lorenzo Corgnati, G.P., 2006. Early forest fires detection: smoke identification through innovative image processing using commercial sensors. Technical Report. Environment Including global Change, Palermo, Italy.

Arrue, 2000 Arrue, B., Ollero, A., Matinez de Dios, J., 2000. An intelligent system for false alarm reduction in infrared forest-fire detection. Intelligent Systems and their Applications, IEEE 15, 6473.

Bodrozic, 2006 Bodrozic, L., Stipanicev, D., Stula, M., 2006. Agent based data collecting in a forest fire monitoring system, in: Software in Telecommunications and Computer Networks, 2006. SoftCOM 2006. International Conference on, IEEE. pp. 326-330.

Bosch, 2007 Bosch, I., Gomez, S., Vergara, L., Moragues, J., 2007. Infrared image processing and its application to forest fire surveillance, in: Advanced Video and Signal Based Surveillance, 2007. AVSS 2007. IEEE Conference on, IEEE. pp. 283-288.

Casbeer, 2005 Casbeer, D., Beard, R., McLain, T., Li, S., Mehra, R., 2005. Forest fire monitoring with multiple small uavs, in: American Control Conference, 2005. Proceedings of the 2005, IEEE. pp. 3530-3535.

Chaczko, 2005 Chaczko, Z., Ahmad, F., 2005. Wireless sensor network based system for fire endangered areas, in: Information Technology and Applications, 2005. ICITA 2005. Third International Conference on, IEEE. pp. 203-207. 
Corsi, 2006 Corsi, N., Gemelli, A., 2006. An innovative approach to forest-fire detection and monitoring: The eu-fire project.

Dios, 1999 Martinez-de Dios, J., Arrue, B., Ollero, A., 1999. Distributed intelligent automatic forest fire detection system. Proceedings of INNOCAP 99.

Dios, 2005 Mart'ınez-de Dios, J., Merino, L., Ollero, A., 2005. Fire detection using autonomous aerial vehicles with infrared and visual cameras, in: Proceedings of the 16th IFAC World Congress.

Doolin, 2005 Doolin, D., Sitar, N., 2005. Wireless sensors for wildfire monitoring, in: Proceedings of SPIE, p. 477.

Hefeeda, 2007 Hefeeda, M., 2007-2008. Forest Fire Modeling and Early Detection using Wireless Sensor Networks. Technical Report. School of Computing Science, Simon Fraser University.

Manyangadze, 2009 Manyangadze, T., 2009. Forest fire detection for near real-time monitoring using geostationary satellites. Technical Report. International Institute for Geo-information Science and Earth Observation, Enschede, Netherlands.

Mitri, 2009 Mitri, G., 2009. Lebanon's National Strategy for Forest Fire Management. Technical Report. Ministry of Environment and AFDC, Beirut.

Kovcs, 2004 Rka Kovcs, Blint Kiss, k.N.G.V., 2004. Early Detection System for vegetation Fire in the Aggtelek National Park. Technical Report. Budapest University of Technology and Economics.

Sahin, 2007 Sahin, Y., 2007. Animals as mobile biological sensors for forest fire detection. Sensors 7, 3084-3099.

Sahin, 2009 Sahin, Y., Ince, T., 2009. Early forest fire detection using radio-acoustic sounding system. Sensors 9, 1485-1498.

Son, 2006 Son, B., Her, Y., Kim, J., 2006. A design and implementation of forest-fires surveillance system based on wireless sensor networks for south korea mountains. IJCSNS 6, 124.

Stipanicev, 2006 Stipanicev, D., Vuko, T., Krstinic, D., Stula, M., Bodrozic, L., 2006. Forest fire protection by advanced video detection system-croatian experiences, in: Third TIEMS WorkshopImprovement of Disaster Management System, Trogir.

Tsiourlis, 2009 Tsiourlis, G., Andreadakis, S., Konstantinidis, P., 2009. Sithon: A wireless network of in situ optical cameras applied to the early detection-notification-monitoring of forest fires. Sensors 9, 4465-4482.

Kelh, 2000 Vin Kelh, Yrj Rauste, A.B., 2000. Forest Fire Detection by Satellites for Fire Control. Technical Report. European Space Agency, Finland.

Yu, $2005 \mathrm{Yu}, \mathrm{L}$. , Wang, N., Meng, X., 2005. Real-time forest fire detection with wireless sensor networks, in: Wireless Communications, Networking and Mobile Computing, 2005. Proceedings. 2005 International Conference on, Ieee. pp. 1214-1217.

Zhou, 2004 Zhou, Y., Chen, S., Zhou, W., Wang, L., 2004. Early warning and monitoring system for forest and grassland fires by remote sensing data, in: Geoscience and Remote Sensing Symposium, 2004. IGARSS'04. Proceedings. 2004 IEEE International, IEEE. pp. 4799-4802. 